\title{
Right atrium compression by a renal cyst: a tomographic diagnosis
}

\author{
Giovanni Fazio, Daniela Bacarella, Giuseppe Lo Re, Emanuele Grassedonio, \\ Massimo Midiri, Paolo Zarcone and Salvatore Novo
}

Journal of Cardiovascular Medicine 2011, 12:148

Keywords: computed tomography scan, echocardiography, renal cyst, right atrium compression

Department of Cardiology and Department of Radiology, University of Palermo, Palermo, Sicily, Italy

Correspondence to Dr Giovanni Fazio, Department of Cardiology, University of Palermo, Via Albiri 3 a, Palermo 90125, Sicily, Italy

Received 23 February 2010 Revised 6 May 2010

Accepted 31 May 2010

Fig. 1

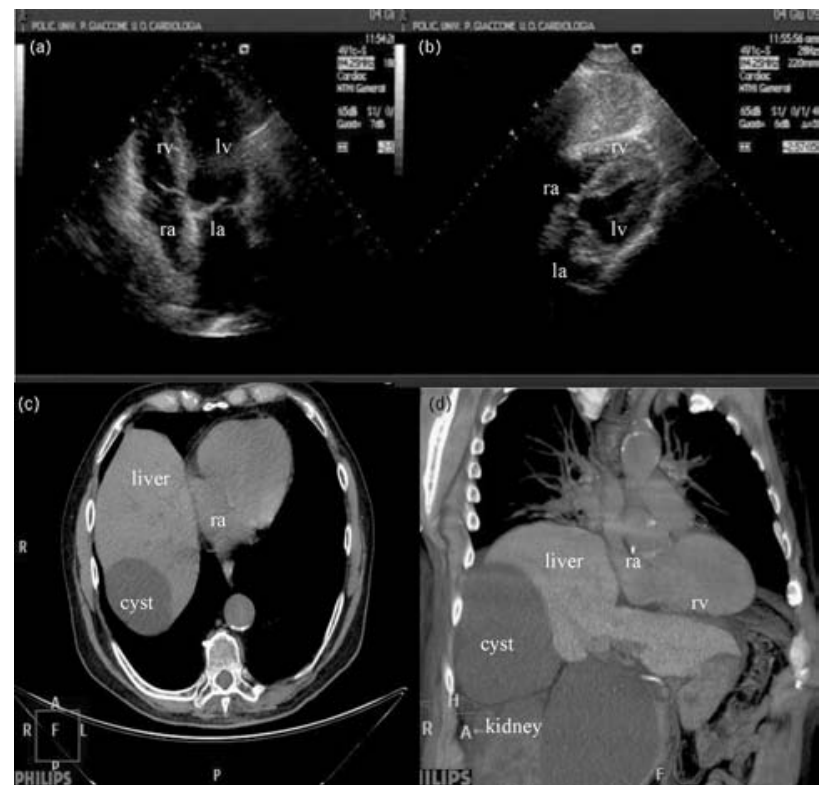

Echocardiographic image and computed tomography of the patient's heart, liver and kidneys. (a) and (b) In four apical chambers and subcostal view, an extrinsic compression of the right atrium (ra) is shown. (c) The upper displacement of the liver that compresses the ra can be noticed. (d) The presence of a large renal cyst is observed, which displaces the liver upward and in medial position, therefore compressing the right heart. la, left atrium; lv, left ventricle; rv, right ventricle.
A 57-year-old, asymptomatic patient was admitted for an occasional echocardiographic control, for arterial hypertension. This examination showed, in four and five apical chamber views, a poorly visualizable right atrium (RA), plausibly compressed by an echorefractive echographical structure such as the liver (Fig. 1). Subcostal and parasternal projections, short axis and long axis, poorly visualized the compressed area. To characterize the unidentified mass, total body computed tomography was suggested; it recognized a bilateral polycystic kidney [1] and, because of the presence of an enormous cyst at the apical area of the right kidney, a thoracic movement of the liver was determined, with consequent compression by the liver on the right lung and heart, and RA in particular. The cyst had a homogeneous structure, its longitudinal diameter was $7.5 \mathrm{~cm}$ and the transverse was $5 \mathrm{~cm}$. Cyst resection was advised.

\section{Reference}

1 Fain O. Renal polycystosis. Rev Prat 2006; 56:939. 